\title{
A RELAÇÃO ENTRE DEFICIÊNCIA FÍSICA E ACESSIBILIDADE NUMA PERSPECTIVA HERMENÊUTICA: A CONSTRUÇÃO DA IGUALDADE A PARTIR DE UMA ÉTICA DA INCLUSÃO; ESTUDO DE UM CASO "FÁCIL"
}

\author{
THE RELATIONSHIP AMONG PHYSICAL \\ DISABILITY AND ACCESSIBILITY IN \\ HERMENEUTIC PERSPECTIVE: THE \\ CONSTRUCTION OF EQUALITY THROUGH AN \\ INCLUSION ETHIC'S; STUDYING AN “EASY” CASE
}

Mateus Costa Pereira

Ronaldo Bastos

Pedro Spíndola B. Alves

\section{RESUMO}

Neste trabalho refletimos sobre o caso de um cidadão que compareceu ao Detran para renovar a sua habilitação, mas que, em virtude de um tratamento discriminatório, é impedido de realizar o teste prático. Pretendemos demonstrar que o caso narrado seria apenas mais um e, absorvido pelo cotidiano, cairia no esquecimento, não fosse a peculiaridade de envolver uma pessoa com deficiência física que somente perseguia o direito de ser tratado como um igual. Sob um enfoque hermenêutico, e tomando a situação concreta como paradigma, o artigo trata da necessidade de construção de uma ética da inclusão social às pessoas com deficiência com fundamento na isonomia - e apenas a isonomia - como um princípio derivado da dignidade da pessoa humana.

Palavras-chave: Pessoa com deficiência. Hermenêutica. Ética da inclusão social. 


\section{ABSTRACT}

This paper assess the case of a person with disabilities and its right to be treated as equal in a matter that the isonomic treatment may demand the disregard of all privileges secured by law. Taking this case as paradigm and based upon the isonomic principle our goal is to point out the necessity of building an inclusion ethic's for people with disabilities. At first sight, what appeared to be an "easy" case reveals the complexity of most cases when confronted by arguments usually neglected by those who don't work through a hermeneutic perspective.

Keywords: People with disabilities. Hermeneutics. Inclusion ethic's.

\section{INTRODUÇÃO}

De um ponto de vista privilegiado e que permita uma introdução da introdução, inicialmente, pretende-se esclarecer o que motivou o presente artigo, o marco inicial que orientou o desenvolvimento de uma incursão que pretende exceder os limites da seara jurídica moderna (formal) para perscrutar um âmbito que - embora não seja prescritivo - se apresenta como feição de nossa época. ${ }^{1}$

Este trabalho não emerge de elucubrações apartadas da realidade, mas exsurge de um caso concreto que expôs a fragilidade de uma situação jurídica e a necessidade de discuti-la. Narrar o caso é, pois, a tarefa deste artigo. Mas não só.

Do estudo do caso emerge um problema central da relação entre a condição física diferenciada de alguém (o que lhe permite ser considerada pessoa com deficiência para fins de direito positivo) e a acessibilidade - garantida juridicamente - aos ambientes e bens jurídicos que não foram pensados para o diferente, mas para o padronizado.

Neste ensaio, são problematizadas as condições em que a relação implicacional entre "deficiência" e "acessibilidade" deve ocorrer, e a partir de que fundamento. O que se pretende, de imediato, é justamente explicitar esse fundamento, para que a mencionada relação possa ser analisada nas linhas desenhadas para sua possibilidade - inclusive jurídica.

O fundamento dessa relação, adiante-se, é o princípio da igualdade, cuja construção possui uma raiz mais profunda na cultura do Ociden- 
te. A existência desse princípio, construído por contingências históricas e sedimentado por esta raiz - a qual representará um fundamento jurídico remoto seu, como veremos -, permite outra construção teórica que se torna determinante para se pensar a questão da acessibilidade de quem não compartilha padrões (físicos, psíquicos etc.) definidos socialmente como "normais"; podemos denominá-la ética da inclusão.

Todos esses aportes teóricos, erigidos pouco a pouco a partir das experiências compartilhadas pela tradição ocidental, servem de subsídio para imprimir de modo indelével na historicidade uma conexão necessária entre "deficiência" e "acessibilidade".

No entanto, pela perspectiva dos autores, a contribuição da Hermenêutica, no âmbito da Filosofia, deve ser tomada de modo extremamente atento e cauteloso para qualquer questão que as "ciências do espírito" busquem analisar. ${ }^{2}$ Para além dessa necessária visitação à Hermenêutica como regra geral aconselhável quando se está diante de quaisquer das ciências humanas, ${ }^{3}$ observar-se-á que a ignorância de seu legado à contemporaneidade leva a distorções das conquistas coletivas de nossa tradição. Apresentar esses movimentos também é objetivo do presente artigo, por necessário para o desfecho da problemática.

\section{A ÉTICA DA INCLUSÃO COMO FRUTO DA TRA- DIÇÃO DO OCIDENTE}

Ao se estabelecer a Hermenêutica como posição teórica, é necessário evidenciar alguns postulados que permitem o enquadramento das ideias aqui expostas numa perspectiva não metafísica e ligada à historicidade. Essa primeira ressalva quanto à necessidade de afastar construções metafísicas não poderia, aqui, ser mais bem sintetizada: ${ }^{4}$

Enquanto hermenêutica, radicaliza-se a superação da metafísica, que, em sua essência, a partir dessa postura, nada mais é do que a permanente tentativa de negação da finitude, superação da temporalidade. Em síntese, metafísica é a pretensão a uma verdade absoluta, e isso significa para a hermenêutica autonegação da finitude.

Depreende-se dessa primeira ressalva que a temporalidade e a finitude são inerentes, não se devendo edificar sistemas totalizantes 
que pretendam oferecer uma verdade atemporal. ${ }^{5}$ A historicidade estabelece a verdade de determinado lugar em determinado tempo e isso é legado por meio da tradição. ${ }^{6}$ Esse legado é apreensível apenas por abrir-se à sua própria época para, por meio da atividade hermenêutica, autointerpretar a faticidade. ${ }^{7}$

Isso é o processo de compreensão ${ }^{8}$ pelo qual se torna possível acessar os valores da tradição a que se pertence.

Para o mundo ocidental, na matéria pertinente a este trabalho, tem-se como valor preponderante legado pela cultura a ideia de inclusão. Tal concepção só pode ser completamente compreendida se se empreender o esforço hermenêutico de acessar a faticidade em suas linhas de interpretação ${ }^{9}$ para desvelar a verdade oferecida pela tradição.

No presente trabalho, tal esforço será implementado. A ética da inclusão presente na tradição ocidental - fruto de um conflituoso e conturbado momento histórico que pode se identificar com o início no Estado Moderno, ganhando contornos mais precisos apenas no segundo pós-guerra do século XX - tem como embasamento fundante o princípio da igualdade. Assim, a análise desse fundamento é necessária para demonstrar os seus contornos.

\section{DA FORMA AO CONTEÚDO, OU DA IGUALDADE À ISONOMIA}

A ideia de igualdade jurídica é uma invenção moderna. Apenas com a ascensão da burguesia é que houve a necessidade de se conferir ao homem esse status, o que foi feito com o objetivo de regular o trabalho livre, mas subordinado, pois somente um homem livre e igual é que poderia dispor do próprio corpo em prol de outrem. ${ }^{10}$ Diferentemente da modernidade, que lida com os assalariados, os antigos conviviam com a escravidão, e o medievo, com a servidão, formas de prestação de trabalho desprovidas de autonomia e vontade e, por conseguinte, de liberdade. De fato, os escravos eram coisas, assim como as mulheres; ${ }^{11}$ já os servos, mormente na Alta Idade Média, embora considerados homens, estavam ligados à terra e eram identificados com ela, de modo que a extinção da terra (ou da posse dela) era o fim do homem. Ambos, escravos e servos, não eram nem livres nem iguais, mas obrigados. Em síntese, o homem 
livre e com pretensões igualitárias, dotado de vontade e com poder de disposição, tal qual o conhecemos, não é uma imagem antiga.

Todavia, a igualdade jurídica, que nasceu com os operários, aos poucos foi estendida a toda a sociedade e de uma maneira cada vez mais profunda, pois a igualdade "formal" - perante a lei - passou a ser, com o tempo, insuficiente, já que gerava injustiças. ${ }^{12}$ É que a igualdade jurídica desconsiderava outras desigualdades, como a social e a cultural. Assim, para mudar esse quadro, era preciso adotar outra perspectiva, e a inspiração não foi nova: Aristóteles e a sua noção de isonomia. Para o estagirita, na análise da igualdade, era preciso considerar a situação das pessoas envolvidas no caso, de modo a ser promovida a igualdade entre os iguais e a desigualdade entre os desiguais, ${ }^{13}$ e esta, na exata medida de suas desigualdades, com o fim de minorar as dessemelhanças naturais e fomentar um equilíbrio jurídico.

Partir da lição de Aristóteles é fundamental porque, a despeito de as políticas afirmativas contribuírem para a correção das desigualdades quando se tornam normas jurídicas, quando tais pretensões se cristalizam - estabelecendo-se como dogmas insuperáveis - podem impedir a correta compreensão do problema trazido à liça. É preciso curar bem o princípio da igualdade e aplicá-lo de forma contextualizada, pois, do contrário, corre-se o risco de violar a própria razão que o estabeleceu.

No caso que será narrado, o princípio da igualdade foi aplicado às avessas; e, para explicitar esse erro e indicar uma postura mais apropriada à justiça no caso concreto, uma postura que concilie teoria e prática, pretende-se defender três teses.

Em primeiro lugar, o princípio da igualdade possui um fundamento jurídico remoto, que é a dignidade da pessoa humana. O princípio da igualdade, segundo o qual todos os homens, pelo simples fato da humanidade, devem ser tratados como sujeitos e, por conseguinte, de forma paritária, nada mais é que uma decorrência do princípio da dignidade. Todavia, a dignidade deve atuar apenas remotamente, haja vista ser um termo abstrato, poroso, indeterminado, aberto e, por isso tudo, problemático, não havendo como controlar as decisões judiciais que o tomam por fundamento.

Em segundo lugar, é preciso tomar a cautela própria de um pensar hermenêutico. A isonomia (ou igualdade material), que é 
uma exceção do ordenamento para dar conta de situações e sujeitos excepcionais, deve ser interpretada com cuidado, pois, se mal aplicada, acaba por dificultar o acesso dos hipossuficientes aos bens jurídicos, paradoxalmente, com fundamento na própria hipossuficiência. Em outras palavras, impossibilita o gozo de um direito com base na própria razão (ratio legis) que inspirou o seu aparecimento/reconhecimento.

Por fim, o direito à acessibilidade deve ser compreendido como uma ampliação dos caminhos, jamais sua restrição. $O$ tratamento diferenciado deve ser reservado àquelas pessoas que não conseguem ter o mesmo acesso aos bens jurídicos que as outras. Isso não quer dizer que esse tratamento tenha que ser o único possível, pois, se um cidadão, embora podendo gozar um direito, não precisar ou reclamar o tratamento diferenciado, não é razoável que ele seja obrigado a receber tal tratamento; a "discriminação positiva" é um direito, uma faculdade de seu titular. Em suma, o fundamento da igualdade material não pode ser a criação de guetos, senão a multiplicidade de caminhos, de vias, acessos.

\section{A DIGNIDADE HUMANA COMO FUNDAMENTO REMOTO DO PRINCÍPIO DA IGUALDADE}

Em geral a doutrina trabalha o conceito de dignidade da pessoa humana sob duas perspectivas, uma positiva e outra negativa. A positiva é aquela que considera a dignidade como aquilo que identifica o ser humano como tal, ou seja, uma dada característica que, caso retirada, inviabilizaria a identificação dos homens como seres humanos, pois estariam tolhidos da sua essência. Essa perspectiva, que chamaríamos de ontológica, normalmente vem amparada pela doutrina kantiana, segundo a qual, no reino dos fins, tudo ou tem um preço ou uma dignidade; o primeiro poderia ser substituído por outro, já a última não. A justificativa é que não podemos tratar os homens (detentores de dignidade) como objetos (que possuem preço), ou, mais propriamente, como um meio para conquistar algo, mas sempre como fim ${ }^{14}$ (causa finalis).

O problema é que, embora variadas áreas do saber tenham buscado dar uma resposta à indagação sobre o que seria a dignidade humana, ou seja, a essência dos homens, a exemplo da religião, da 
filosofia e da ciência, ${ }^{15}$ ao que parece, nenhuma delas conseguiu dar conta da empresa, não por fragilidades em seus postulados teóricos, mas por dificuldades apresentadas pelo próprio termo.

De fato, a dignidade é um conceito vago e impreciso, ambíguo e poroso. Em razão disso é que parte da doutrina prefere trabalhar com uma perspectiva negativa, investigando não o que é a dignidade humana, mas o que ela não é, o que também conduz ao mesmo problema ontológico da vertente positiva, só que às avessas. Não se altera o problema, apenas inverte-se o lado. Enquanto uma (a positiva) pesquisa o que seria a essência dos homens, a outra (a negativa) investiga o que ela não é.

O que se propõe neste artigo não é a discussão sobre o conteúdo (apriorístico) da dignidade humana, porque discutir o quid est da dignidade pode vir a se tornar um debate metafísico interminável e, embora a especulação sem um termo prévio seja o papel da Filosofia, certamente não o é da Filosofia do Direito, que precisa resolver conflitos reais e não apenas hipotéticos. Nosso objetivo é abordar uma nova perspectiva da dignidade da pessoa humana, preocupada com as formas de concretização histórico-cultural do preceito - possível por meio da transferência do seu ethos para princípios derivados com a sua elaboração teórica e mostrar como essa abordagem facilita a interpretação e solução do caso trabalhado.

No prisma eleito, a dignidade da pessoa humana deve ser simultaneamente limite e tarefa do Estado, ${ }^{16}$ tornando-se tema crucial de direito público, o que não quer dizer que deva ser afastada da Filosofia, que é matéria fundamental para a discussão humanista. O que é notável é que a Filosofia se torna um saber estéril, se o objetivo é dar a dimensão jurídica de um preceito e lhe garantir efetividade. Daí, quando o problema é resolver os conflitos sociais, os juristas têm muito mais capacidade para dar conta dele do que os filósofos, o que não significa que os argumentos jurídicos não tenham base filosófica.

Para tornar a dignidade da pessoa humana um preceito efetivo, e não somente programático, é preciso tomá-la, em primeiro lugar, como um pendão hermenêutico capaz de medir a higidez do sistema normativo e, em segundo lugar, como parâmetro axiológico para princípios dela derivados. Essa postura é importante para evitar que 
o preceito da dignidade humana tenha a mesma banalização que hoje têm os "princípios" da razoabilidade e da proporcionalidade, os quais se tornaram justificativa para o abandono das regras e a adoção de decisões tão somente principiológicas, o que faz com que os julgamentos "escapem" totalmente ao controle da sociedade. Isso porque "[...] não é qualquer princípio que pode ser invocado para justificar a não aplicação das regras; caso contrário, nenhuma regra estaria imune". ${ }^{17}$ Existem princípios que são mais amplos e verticalmente mais profundos em relação a outros e, por isso, estruturam o ordenamento; mais que um dever ser, eles são um querer ser, opções valorativas de um poder que representa o querer nacional. ${ }^{18}$ Sem sombra de dúvida, a dignidade da pessoa humana e os seus princípios derivados são exemplos destes. Não por outro motivo a dignidade humana foi erigida a fundamento do Estado Democrático de Direito (art. 1º, III, CF/88).

Quando a decisão se forma a partir de bases apenas abstratas, ela escapa ao controle do Direito, podendo gerar um decisionismo sem limites. Como, em geral, não existem regras formuladas com base na razoabilidade ou na proporcionalidade, estes são princípios que só irão operar para avaliar o bom senso do comando normativo, ou seja, atuam apenas a posteriori, exercendo uma função de controle, mas a sua aplicação, contraditoriamente, escapa ao controle do próprio Direito e também da sociedade, pois o que é razoável para um (o legislador) pode não ser para outro (o julgador), ${ }^{19}$ e ninguém pode contestar juridicamente a (ir)razoabilidade da toga, mormente em última instância.

Não existem critérios objetivos para determinar, em casos como este, como o Direito deverá ser aplicado. É que, quando se trata da aplicação de princípios que são fundantes de um dado sistema normativo, se faz necessário se valer de outros menos abstratos, aqui chamados de derivados, para fundamentar a decisão, com o fim de conferir à sociedade poderes para aferir tanto se o legislador criou uma regra coerente com a razão que o inspirou quanto se o juiz julgou a regra a partir da mesma razão.

Ao contrário do que acima foi descrito, existem regras criadas com base na igualdade, liberdade, propriedade e, assim, apenas remotamente, na dignidade humana. São essas normas que poderão receber um controle a partir da análise da coerência entre o disposto no preceito 
normativo e a razão que o fundou. Assim, o nosso argumento é que a dignidade da pessoa humana, por ser um princípio cuja delimitação apriorística é muito difícil de ser realizada (afinal, ela é um princípio fundante), tem que ser aferida a partir de princípios derivados, pois, pela sua abertura axiológica, a dignidade poderia ser argumento para qualquer tipo de decisão - como acontece com a razoabilidade e a proporcionalidade -, escapando ao controle social.

O princípio da igualdade seria um destes princípios derivados da dignidade humana ${ }^{20}$ e, dessa monta, responsável por aferir se uma regra inspirada no paradigma igualitário mantém coerência com ele. $\mathrm{Na}$ análise de caso desenvolvida neste artigo, que envolve o problema da acessibilidade aos bens jurídicos por parte das pessoas com deficiência, o julgador teria que analisar o fundamento que estabeleceu a regra e, caso constatasse que ela teria sido criada com base no paradigma da igualdade, a regra (qualquer que seja ela) deveria assegurar "A plena e efetiva participação e inclusão na sociedade" (art. $3^{\circ}$, letra "c", Princípios Gerais, Dec. $n^{\circ}$ 6.949/09), ou seja, promover o acesso mais amplo possível às pessoas hipervulneráveis, em obediência ao princípio da igualdade, que repudia qualquer tipo de discriminação negativa. ${ }^{21}$ Em decisão em sede de recurso especial, o Superior Tribunal de Justiça já asseverou que, em casos desse jaez, é preciso ter cautela hermenêutica, como a defendida aqui, traduzida "[...] no mandamento de atribuir à norma que requer interpretação ou integração o sentido que melhor e mais largamente ampare os direitos e interesses das pessoas com deficiência". ${ }^{22}$

A dignidade da pessoa humana é o fundamento do caso, mas funciona como uma motivação remota, "por ricochete", subsidiária, haja vista sua hipótese de incidência ser muito flexível - impossível de ser determinada antes da concretização normativa -, não servindo, pois, como norma de decisão. O caso discutido a partir do próximo tópico obedece ao princípio da igualdade e é sob a sua égide que deve ser interpretado, mesmo que ele tenha se originado do paradigma (ethos) da dignidade. Com base no princípio da igualdade, qualquer regra que trate da temática da acessibilidade e inclusão social das pessoas com deficiência deve conferir o mais amplo acesso aos bens jurídicos comunitários, o que inclui, a contrario sensu, e no mínimo, o mesmo acesso dado às pessoas sem deficiência. ${ }^{23}$ 


\section{O CASO E O OCASO: UMA PESSOA COM DEFI- CIÊNCIA IMPEDIDA DE RENOVAR A CARTEIRA NACIONAL DE HABILITAÇÃO}

No ano de 2009, após mais de 25 anos desempenhando a profissão de motorista, uma pessoa com deficiência foi surpreendida pelo órgão de fiscalização de trânsito quando da renovação de sua Carteira Nacional de Habilitação $(\mathrm{CNH}) \cdot{ }^{24}$ Em específico, sua surpresa decorreu da imposição do Detran no tocante à realização do teste prático em veículo adaptado; cuidando-se de uma pessoa com deficiência, atrofia parcial na perna esquerda, fruto de uma paralisia infantil, segundo os fiscais do órgão, a adaptação se impunha.

A situação gerou alguma perplexidade naquele motorista; perplexidade fundada na ausência de imposição semelhante no pretérito. $\mathrm{O}$ condutor nunca tinha dirigido um veículo adaptado, sequer ingressado em um. A despeito de reclamar a todo tempo pela realização em um veículo normal, como qualquer outra pessoa prestaria o teste, amargando sistemáticas negativas, só lhe restaria prestar uma reclamação na Ouvidoria do órgão, mas que jamais surtiria qualquer efeito...

Em particular, o caso seria apenas mais um, trivializado pelo universo das situações cotidianas, acaso não envolvesse pessoa fora de um "padrão" estabelecido e, pois, enxergado como "deficiente" portador de deficiência, portador de necessidades especiais (rectius: pessoa com deficiência). Todavia, na situação em comento, a única coisa que o motorista de táxi pretendia era seu reconhecimento como igual. Mas não foi o que aconteceu. Foi vítima da própria prerrogativa, sendo marginalizado, não por querer ser diferente, senão por exibir condições de igualdade.

Sem resolver a questão em âmbito administrativo, a celeuma foi transportada ao Poder Judiciário. Sobre a novela quanto ao reconhecimento de seus direitos na seara jurisdicional, não convém alongar o drama. O que releva na espécie é a equivocada compreensão da disciplina infralegal sobre o tema, notadamente, a Resolução nº 267/2008/ CONTRAN. Não sendo de nosso propósito uma reflexão sobre o ato normativo em destaque, registre-se apenas que ele foi editado a fim de regularizar a situação de pessoas com deficiência em profissões 
atreladas à condução de veículos. Para tanto, e conforme o caso, era suficiente que o veículo fosse adaptado. É o que basta relatar.

\section{A relação entre deficiência e acessibilidade como um problema hermenêutico: a contradição entre a interpretação/concretização de uma regra e a ratio legis que a fundamentou}

Sob a égide da isonomia em sentido material, foram instituídas leis à defesa e promoção da dignidade da pessoa com deficiência. Por óbvio que a intenção do legislador foi a de criar condições ao exercício pleno da cidadania. Cuida-se do beneficio de inclusão social, previsto no plano constitucional - mormente com o advento da Convenção sobre os Direitos da Pessoa com Deficiência, tratado de direitos humanos aprovado em nosso país sob as especiais condições estabelecidas no art. $5^{\circ}, \S 3^{\circ}$, da Constituição Federal (Decreto Legislativo $n^{\circ} 186 / 08$; Decreto Presidencial n ${ }^{0}$ 6.949/09); ${ }^{25}$ integrante do "bloco de constitucionalidade" 26 - mas que reclama integração no plano infraconstitucional, não para dar eficácia, já que, por sua natureza, os preceitos ostentam incidência imediata e aplicabilidade direta, senão para dar a máxima efetividade a seus comandos.

No particular, um tratamento isonômico se sugere diferenciado, tendo em vista as dificuldades de acessibilidade enfrentadas pelas pessoas com deficiência nas atividades do cotidiano em geral; tratamento diferenciado para garantir a inclusão social no trabalho. Como antevisto, data de um passado remoto a noção de isonomia como a igualdade entre os iguais e a desigualdade entre os desiguais... Com a modernidade, operou-se o turvamento dessa concepção em nome de outras ideologias, sendo digno de nota o advento da codificação napoleônica.

Com efeito, sensível a essa situação, já ao tempo da Lei $\mathrm{n}^{\mathrm{o}}$ $7.853 / 89,27$ o legislador editou diretrizes fundamentais ao Estado - no desempenho de função legislativa, administrativa ou jurisdicional -, bem como à sociedade, no tratamento das pessoas com deficiência. Outros tantos atos normativos foram editados sob a égide daquilo que se entende por paradigma integracionista, mas a temática ganhou contorno acentuado e sofisticado - já num paradigma de inclusão social $^{28}$ - com o advento da mencionada Convenção (Decreto Legislativo $\mathrm{n}^{\mathrm{o}}$ 186/08; Decreto Presidencial $n^{\mathrm{o}}$ 6.949/09). ${ }^{29}$ Embora se pretenda 
ressuscitar um debate já superado dentre a mens legis e a mens legislatoris, ${ }^{30}$ importa referir que, sobretudo no último diploma, foi encartado um critério valorativo, hermenêutico, prestando-se, pois, como parâmetro de toda e qualquer atividade estatal ou não na interpretação/ concretização $^{31}$ da lei. Poder-se-iam transcrever diferentes preceitos, mas apenas alguns serão focalizados:

Preâmbulo

$[\ldots]$

n) Reconhecendo a importância, para as pessoas com deficiência, de sua autonomia e independência individuais, inclusive da liberdade para fazer as próprias escolhas,

$[\ldots]$.

Artigo 3

Princípios gerais

$[\ldots] ;$

d) O respeito pela diferença e pela aceitação das pessoas com deficiência como parte da diversidade humana e da humanidade;

e) A igualdade de oportunidades;

f) A acessibilidade;

$[\ldots]$.

De logo se afere que, ao Estado, seja por sua administração direta, seja descentralizada, quando atua para concretizar o primado da isonomia, instituindo direitos e prevendo garantias - ou em recuo, a própria dignidade da pessoa humana (cf. seção 2) -, não compete impor um determinado caminho ou condição à pessoa com deficiência. Em verdade, salvo algumas exceções, é frágil a ideia de exercício de direitos contra a vontade de seu titular. Sabe-se, inclusive, que nem todos os direitos positivados na Constituição sob o rótulo de fundamentais ${ }^{32}$ ostentam conteúdo absoluto, sendo certo que há uma limitação recíproca dentre esses direitos. ${ }^{33}$

No campo das pessoas com deficiência, a função estatal deve ter em mira a ampliação do leque - das vias de acesso ao exercício pleno da cidadania -, o qual, por natureza, no mais das vezes é restri- 
to; jamais reduzi-lo a um caminho único. É importante esse cuidado hermenêutico, pois, após um longo período em que o Estado fechou os olhos para determinadas classes de pessoas (dentre elas, em pauta, as pessoas com deficiência), ${ }^{34}$ com muito esforço algumas delas lograram se adaptar (as próprias pessoas, e não os ambientes), vencendo todas as adversidades que o meio social apresentava e continua a apresentar (por preconceito ou ignorância). Quanto a essas, uma atuação precipitada do Estado, sem conhecimento de causa, sobre não the adjudicar benefícios, ainda poderá comprometer o exercício daqueles já conquistados. Estar-se-ia, por assim dizer, amputando a dignidade já exercida, ${ }^{35}$ tal como ocorrido.

Dessa feita, o Estado não pode impor a acessibilidade, pois se trata, com o perdão da tautologia, de um direito das pessoas. No escopo de fazer o bem, o Estado não pode acreditar que a deficiência sempre imponha um tratamento diferenciado, quando então a discriminação, abandonando seu caráter positivo, torna-se negativa. Noutros termos, admitir que as pessoas com deficiência tenham reconhecido seu direito à diferença não implica, automaticamente, a assunção de que o elemento diferenciador sempre estaria presente ${ }^{36}$ - essa perspectiva tem seu argumento construído com os olhos voltados ao caso concreto, mas, em linha de princípio, aplica-se às diferentes situações.

É possível fazer um contraponto com conhecida doutrina, quando afirma que somente se pode interpretar como desigualdades certas situações quando a lei houver "assumido" o fator tido como desequiparador. ${ }^{37}$ Indo além, somente após uma análise empírica, que examine se o fator discriminante é faticamente relevante, será possível proceder à interpretação/concretização como desigualdades de outras situações. ${ }^{38}$

Nessa esteira, o tratamento diferenciado deve ser assegurado para equiparar oportunidades e/ou conferir igualdade de condições, caso necessário. ${ }^{39}$ Conseguintemente, não havendo necessidade de medidas conducentes à "equiparação" ou "igualdade", não há razão para o discrimen. Tudo isso sob pena de ocorrer uma discriminação em cima de nova discriminação - "discriminação de segunda ordem" -, fulminando-se a conquista já existente. O raciocínio tem inteira aplicação ao caso relatado, ${ }^{40}$ mas outro exemplo poderá auxiliar a compreensão. 
Tomando em consideração a imposição normativa quanto à construção de rampas de acesso em locais públicos e privados, seria possível impor a uma determinada pessoa com deficiência a utilização da rampa? E se a rampa for desnecessária? Doutro giro, uma pessoa com deficiência é obrigada a utilizar o assento reservado no transporte público?

Lamentavelmente, a atuação do Estado no caso discutido foi justamente no sentido contrário, revelando um completo desconhecimento de causa. Salvo melhor juízo, somente após a realização do teste prático, poder-se-ia afirmar que o condutor é apto, apto com restrições, inapto temporário, ou mesmo inapto, tudo conforme o art. $8^{\circ}$ da mencionada Resolução no $267 / 2008$ / CONTRAN. ${ }^{41}$

No caso concreto, a exigência normativa, que é originária do direito à inclusão no trabalho, foi interpretada/aplicada em acinte ao princípio da igualdade e, em última instância, à própria dignidade da pessoa humana. Em outros dizeres, o raciocínio nos conduz - após a verificação da isonomia e o direito à diferença - ao valor que, positivado, dá origem a todos os demais princípios. ${ }^{42}$ Por oportuno, lembremos, com Dworkin, que é preciso ter coerência, aqui entendida “[...] como coerência na aplicação do princípio que se tomou por base, e não apenas na aplicação da regra específica enunciada em nome desse princípio". ${ }^{43}$ No caso, a deficiência física deu mote ao bloqueio de um bem jurídico que todos os outros cidadãos, pessoas sem deficiência, possuem. Além de não propiciar a igualdade, a aplicação equivocada da regra disseminou a desigualdade, só que para o lado errado, contrariando tanto o Direito (cuja teoria da "discriminação positiva" visa a corrigir as desigualdades) quanto à Filosofia (notadamente, a equidade aristotélica).

O que se mostra interessante, para retomar o tema da dignidade humana, é que, se a norma de decisão fosse baseada no princípio da dignidade, o intérprete estaria de mãos atadas, pois, como ele é muito aberto e abstrato, seria deveras mais difícil estabelecer alguma inferência lógica; inclusive, cogitar-se-ia de argumentos em sentido oposto, como o respeito à dignidade dos passageiros etc. Ao revés, como o paradigma está na igualdade, salta aos olhos a falta de coerência do administrador - in casu, o Detran - quando da aplicação da regra. 
Assim, o que era um caso, aparentemente, de fácil resolução conseguiu se tornar difícil, requerendo uma variedade de argumentos que, a priori, seria impossível de imaginar. Já em sede de conclusão do artigo, é sobre esta distinção - entre casos fáceis e difíceis - que se discutirá na próxima seção, em nova crítica, defendendo que se trata de um falso problema; não se pode definir antecipadamente o que seja um caso fácil ou difícil, já que isso depende da capacidade dos sujeitos que participam do discurso; ademais, se há clareza em determinado posicionamento, é devido à qualidade do(s) argumento(s), e não a uma suposta autoevidência da norma que, por ter essa qualidade, não precisaria ser interpretada. Ainda se crê em meras subsunções normativas?

\section{CONSIDERAÇÕES FINAIS: A DISTINÇÃO ENTRE CASOS “FÁCEIS" E "DIFÍCEIS" COMO UM FALSO PROBLEMA}

Casos difíceis são comumente definidos como aqueles em que a liberdade do julgador é grande, justamente porque não existe uma solução explícita no ordenamento, ${ }^{44}$ ao passo que casos fáceis seriam, por exclusão lógica, aqueles em que o ordenamento apresenta uma solução notória, a tal ponto que qualquer estudante de Direito conseguiria resolvê-los sem maiores constrangimentos.

O problema é que a distinção dentre casos fáceis e difíceis parece ser despropositada, porque a complexidade de um caso não é dada objetivamente; a sua configuração depende da capacidade cognitiva de cada julgador e da habilidade argumentativa dos advogados. É claro que existem casos reconhecidamente fáceis e outros reconhecidamente difíceis, e quanto a esses não há tanta discussão. O debate gira em torno da zona cinzenta onde a classificação dentre fáceis e difíceis varia de acordo com a capacidade dos utentes (os sujeitos do discurso) e com o contexto social (tempo e espaço) em que ocorre o julgamento.

Assim, é impossível determinar previamente a densidade de um caso, dentre outros motivos porque as normas não são autoevidentes ou autoexplicativas. $\mathrm{O}$ conhecimento que temos sobre determinada norma já vem impregnado de uma série de concepções próprias 
daquele que a interpreta. O direito não é estático, mas circular; é um constante fazer que nunca chega a um termo. Ao mesmo tempo em que o julgador se diz subordinado à Constituição, ele também a constrói quando interpreta as suas normas, de modo que hoje temos "mais" Constituição que em 1988.

Nesse sentido, não é possível afirmar que, na clareza normativa, não é necessário valer-se da interpretação, porque se algo está claro é porque já foi interpretado - o in claris cessat interpretatio dos franceses, na verdade, é uma falácia que esconde uma argumentação vitoriosa. Em todos os casos há argumentação, nos fáceis e nos difíceis; acontece que nos últimos a multiplicidade de argumentos tem que ser maior devido à variedade de alternativas que podem ser escolhidas para a sua solução. E mais, mesmo um caso aparentemente fácil, trivializado pelo senso comum, pode se tornar difícil quando mal interpretado.

$\mathrm{Na}$ análise de caso elaborado neste artigo - caso que aparentava ser simples - pôde-se constatar que a falha da interpretação/aplicação da regra, divorciada da ratio que a inspirou, negligenciando a inclusão social já existente e, pois, a desnecessidade da discriminação, impôs ainda maior dificuldade de acesso à pessoa com deficiência. Como consequência, ainda acarretaria um prejuízo maior que aquele que pretendia remediar.

\section{NOTAS}

1 O que aqui se busca trazer à baila é a noção desenvolvida pela hermenêutica: "Segundo ele (Dilthey). (época) é essa estrutura que tem centro em si mesma e por isso interliga num todo único todas as suas manifestações. Cada pessoa que nela vive tem em comum a medida das suas ações, de seus sentimentos e sua compreensão. A tarefa da análise histórica é rastrear a coincidência de objetivos, valores e modos de pensar que constituem, pois é só em relação com a estrutura total da. Que se pode calcular a importância da contribuição de um indivíduo (Der Aufbau der geschichlichen Welt, em Gesamelte Schriften, VII, p.155)" (ABBAGNANO, Nicola. Dicionário de filosofia. São Paulo: Martins Fontes, 2007. p. 395).

2 Com Dilthey, as Geisteswissenschaften são propostas como eminentemente interpretativas, e a necessidade de compreensão é algo que as une, já que, em todas elas, os significados de seus objetos de análise são construídos coletivamente e não retirados da natureza (Cf.: DILTHEY, Wilhelm. Introdução às ciências humanas: tentativa de uma fundamentação para o estudo da sociedade e da história. Rio de Janeiro: Editora Forense Universitária, 2010).

3 Lembrando a lição de Nelson Saldanha de que a Hermenêutica não está referida apenas a textos; ela funda a interpretação e se reporta a qualquer problema cultural, haja ou não textos (SALDANHA, Nelson Nogueira. Ordem e hermenêutica. 2. ed. Rio de Janeiro: Renovar, 2003. p. 228). 
A relação entre deficiência física e acessibilidade numa perspectiva hermenêutica: a construção da igualdade a partir de uma ética da inclusão; estudo de um caso "fácil" rânea. 3. ed. São Paulo: Edições Loyola, 2006. p. 231.

5 No escólio de Nelson Saldanha: “[...]. Nossa época, carregada de consciência histórica, convida os pensadores do Direito a compreender que a historicidade do saber jurídico - como a da experiência, e a dos conceitos - significa a um tempo a perecibilidade das formas que ele assume e a permanência dos problemas maiores que o motivam" (SALDANHA, Nelson Nogueira. Teoria do direito e crítica histórica. Rio de Janeiro: Freitas Bastos, 1987. p. 93).

6 REALE, Giovanni; ANTISERI, Dario. História da filosofia. São Paulo: Paulus, 1991. v. III, p. 633-635.

7 HEIDEGGER, Martin. Ontologia: hermenêutica da faticidade. Petrópolis: Editora Vozes, 2012. p. 21-27.

8 Que na Hermenêutica se torna pré-compreensão, ou antecipação: “Tendo enfatizado o papel que desempenham, no âmbito dos procedimentos de nossa compreensão, certas antecipações absolutamente fundamentais, isto é, comuns a todos nós, podemos agora definir mais exatamente o sentido do fenômeno de 'pertencimento', ou seja, o fator tradição no comportamento histórico-hermenêutico. A hermenêutica deve partir do fato de que compreender é estar em relação, a um só tempo, com a coisa mesma que se manifesta através da tradição e com uma tradição de onde a 'coisa' possa me falar" (GADAMER, Hans-Georg. O problema da consciência histórica. 3. ed. Rio de Janeiro: Editora FGV, 2009. p. 67).

9 HEIDEGGER, Martin, op. cit. p. 42-46.

10 BASTOS, Ronaldo. O conceito do direito em Marx. Porto Alegre: Sergio Antonio Fabris Ed., 2012. p. 101.

11 LEI DAS DOZE TÁBUAS. Tábula 06, ponto 6. "A mulher que residir durante um ano em casa de um homem, como se fora sua esposa, será adquirida por esse homem e cairá sob o seu poder, salvo se se ausentar da casa por três noites".

12 Sobre a preocupação de previsibilidade e segurança jurídica preconizadas pelo positivismo jurídico e sua relação com a isonomia em sentido formal, cf. DIMOULIS, Dimitri. Positivismo jurídico: introdução a uma teoria do direito e defesa do pragmatismo jurídico-político. São Paulo: Método, 2006. p. 198.

13 " [...] a mesma igualdade será observada entre as pessoas e as coisas envolvidas, pois do mesmo modo que as últimas (as coisas envolvidas) são relacionadas entre si, as primeiras também o são. Se as pessoas não são iguais, não receberão coisas iguais" (ARISTÓTELES, Ética a Nicômaco, p. 109).

14 Kant usa um imperativo categórico para sintetizar essa perspectiva, qual seja: "Age de tal maneira que possa usar a humanidade, tanto em tua pessoa como na pessoa de qualquer outro, sempre e simultaneamente como fim e nunca simplesmente como meio (KANT, Immanuel. Fundamentação da metafísica dos costumes e outros escritos. Tradução de. Leopoldo Holzbach. São Paulo: Martin Claret, 2006. p. 59).

15 COMPARATO, Fabio Konder. A afirmação histórica dos direitos humanos. 6 ed. rev. e atual. São Paulo: Saraiva, 2008. p. 1.

16 SARLET, Ingo Wolfgang. As dimensões da dignidade da pessoa humana: construindo uma compreensão jurídico-constitucional necessária e possível. Revista Brasileira de Direito Constitucional, São Paulo, n. 9, p. 379, jan./jun. 2007.

17 DWORKIN, Ronald. Levando os direitos a sério. Tradução de Nelson Boeira. São Paulo: Martins Fontes, 2005. p. 60.

18 REGO, G. B. Os princípios fundamentais e sua natureza estruturante na constituição de 1988. Anuário dos Cursos de Pós-Graduação em Direito, Recife: Editora Universitária da UFPE, ano 8, n. 8, p. 124, 1999.

19 Como percebe Descartes, "[...] o bom senso é a coisa do mundo mais bem distribuída, porquanto cada um acredita estar tão bem provido dele que, mesmo aqueles que são os mais difíceis de contentar em qualquer coisa, não costumam desejar tê-lo mais do que já o têm" (DESCARTES, René. O discurso do método. São Paulo: Ed. Escala, [s/d], p. 13).

20 Cf. BODIN DE MORAES, M. C. O conceito de dignidade humana: substrato axiológico e conteúdo normativo. In: SARLET, Ingo Wofgang (Org.). Constituição, direitos fundamentais e direito privado. Porto Alegre: Livraria do Advogado, 2003. p. 116 e ss. 
21 No ensejo, a Convenção sobre os Direitos da Pessoa com Deficiência (Dec. nº 6.949/09, art. $2^{\circ}$ ) estabelece que “Discriminação por motivo de deficiência' significa qualquer diferenciação, exclusão ou restrição baseada em deficiência, com o propósito ou efeito de impedir ou impossibilitar o reconhecimento, o desfrute ou o exercício, em igualdade de oportunidades com as demais pessoas, de todos os direitos humanos e liberdades fundamentais nos âmbitos político, econômico, social, cultural, civil ou qualquer outro. Abrange todas as formas de discriminação, inclusive a recusa de adaptação razoável".

22 SUPERIOR TRIBUNAL DE JUSTIÇA. Resp $\mathbf{n}^{0}$ 931.513/RS, Rel. Min. Carlos Fernando Mathias, Rel. para o acórdão Min. Herman Benjamin.

23 É o que deflui, por força da isonomia, no que se entende por "igualdade de condições" e "equiparação de oportunidades".

24 Sobre a condição desse motorista, para um critério objetivo de sua qualificação, importante mencionar que, ostentando habilitação à condução de caminhões - ofício que realizou por um determinado período -, já desempenhava a profissão de taxista há mais de 15 anos.

25 Sobre o tema, cf. PEREIRA, Mateus Costa; ALVES, Pedro Spíndola. Bezerra. A dignidade da pessoa humana com deficiência: reflexos práticos da acessibilidade enquanto direito fundamental. Revista Brasileira de Tradução Visual (RBTV), v. 14, p. 1-16, 2013.

26 DIMOULIS, Dimitri; MARTINS, Leonardo. Teoria geral dos direitos fundamentais. São Paulo: RT, 2008. p. 49-50.

27 “O escopo dessa lei foi conferir proteção jurídica diferenciada aos deficientes físicos, mentais ou sensoriais, o que se impõe justamente para compensar essas deficiências em prol da igualdade substancial" (ALMEIDA, Gregório Assagra de. Direito material coletivo: superação da Summa Divisio Direito Público e Direito Privado por uma nova Summa Divisio Constitucionalidade. Belo Horizonte: Del Rey, 2008. p. 556).

28 Sobre a diferença dentre esses paradigmas, vale a pena conferir a literatura específica. Por todos: SASSAKI, Romeu Kazumi. Inclusão: construindo uma sociedade para todos. 8. ed. Rio de Janeiro: WVA, 2010. p. 34 e ss.

29 Tratando da importância da Convenção e focando no conceito de pessoa com deficiência, cf. PEREIRA, Mateus Costa; SPÍNDOLA, Pedro Bezerra Alves. Redefinição constitucional de pessoa com deficiência e o direito à diferença. Revista Brasileira de Tradução Visual (RBTV), v. 15, p. 18-35, 2013.

30 Cf. FERRAZ JUNIOR., Tércio Sampaio. Introdução ao estudo do direito: técnica, decisão, dominação. 4. ed. São Paulo: Atlas, 2003. p. 264 e ss.

31 GRAU, Eros Roberto. Ensaio e discurso sobre a interpretação/aplicação do direito. 3. ed. São Paulo: Malheiros, 2005. p. 25.

32 Sem perder de vista a falta de critério do legislador na excessiva abrangência do rol constitucional. Nesse sentido: MARMELSTEIN, George. Curso de direitos fundamentais. 3. ed. São Paulo: Atlas, 2011. p. 23. Ver, ainda, a distinção dentre os sentidos formal e material dos direitos fundamentais. Cf. MARINONI, Luiz Guilherme. Teoria geral do processo. 2. ed. São Paulo: RT, 2006. p. 66 e ss.

33 Sobre a restringibilidade dos direitos fundamentais, cf. ALEXY, Robert. Teoria dos direitos fundamentais. 2. ed. Tradução de Virgílio Afonso da Silva. São Paulo: Malheiros, 2011. p. 276 e ss. SILVA, Virgílio Afonso da. Direitos fundamentais: conteúdo essencial, restrições e eficácia. São Paulo: Malheiros, 2009. p. 126 e ss. Também no sentido do texto, dissertando os "direitos da personalidade", cf. CANTALI, Fernanda Borghetti. Direitos da personalidade: disponibilidade relativa, autonomia privada e dignidade humana. Porto Alegre: Livraria do Advogado, 2009. p. 136.

34 Vale registrar que a mola propulsora ao desenvolvimento dos direitos dos deficientes foi o período do pós-guerra, na medida em que vários militares norte-americanos que prestaram serviço na Segunda Grande Guerra regressaram àquele país com variadas sequelas dos combates.

35 Na arguta observação de Sarlet: “[...]. Como tarefa (prestação) imposta ao Estado, a dignidade da pessoa humana reclama que este guie as suas ações no sentido de preservar a dignidade existente, quanto objetivando a promoção da dignidade, especialmente criando condições que possibilitem o pleno exercício e fruição da dignidade, sendo portanto depen- 
dente (a dignidade) da ordem comunitária, já que é de se perquirir até que ponto é possível ao indivíduo realizar, ele próprio, parcial ou totalmente, suas necessidades existenciais básicas ou se necessita, para tanto, do concurso do Estado ou da comunidade (este seria, portanto, o elemento mutável da dignidade), constatação esta que remete a uma conexão com o principio da subsidiariedade, que assume uma função relevante também neste contexto" (SARLET, Ingo Wolfgang. Dignidade da pessoa humana e direitos fundamentais na Constituição Federal de 1988. Porto Alegre: Livraria do Advogado, 2009. p. 53).

36 Sobre esse direito à diferença e seus reflexos, cf. ALMEIDA, Gregório Assagra de, op. cit., p. 557.

37 MELLO, Celso Antônio Bandeira de. Conteúdo jurídico do princípio da igualdade. 3. ed. São Paulo: Malheiros, 2006. p. 45.

38 Acaso fosse nosso intento trabalhar com a razoabilidade, conforme preleção de Humberto Ávila, a razoabilidade reclama a tomada de consideração de aspectos individuais do caso concreto, quando essas peculiaridades são desconsideradas pela generalização legal. Assim, mesmo que preenchidas as condições de incidência da "norma geral", por se tratar de um "caso anormal", as especificidades presentes na situação inibem a sua aplicação. (ÁVILA, Humberto. Teoria dos princípios: da definição à aplicação dos princípios jurídicos. 11. ed. São Paulo: Malheiros, 2010. p. 156).

39 " [...] para compensar a deficiência fática que sofrem algumas pessoas, devem-se assegurar, em seu favor, medidas protetivas, visando suprir essa deficiência fática que os impede de assumir por si mesmas a defesa ou o exercício de seus próprios interesses ou direitos" (MAZZILI, Hugo Nigro. A defesa dos interesses difusos em juízo: meio ambiente, consumidor, patrimônio cultural e patrimônio público e outros interesses. 15. ed. São Paulo: Saraiva, 2002. p. 476).

40 Se a atrofia parcial da perna esquerda nunca prejudicou o motorista ao exercício da profissão, por que lhe impor a realização do teste em um veículo adaptado? Na medida em que a atrofia do motorista não lhe impossibilitou de se incluir socialmente, não há qualquer justificativa para rotulá-lo. Ora, a discriminação positiva tem pertinência quando houver a necessidade de equiparação, isto é, o dissertar da equiparação pressupõe não apenas a diferença, senão que essa diferença seja juridicamente relevante no caso sob exame. Mesmo porque, a aplicação "cega" da lei leva ao absurdo de espezinhar as próprias razões que a inspiraram. Mais uma vez, com Ávila: “Uma regra não é aplicável somente porque as condições previstas em sua hipótese são satisfeitas. Uma regra é aplicável a um caso se, e somente se, suas condições são satisfeitas e sua aplicação não é excluída pela razão motivadora da própria regra ou pela existência de um princípio que institua uma razão contrária. Nessas hipóteses as condições de aplicação da regra são satisfeitas, mas a regra, mesmo assim, não é aplicada" (ÁVILA, Humberto, op. cit., p. 156).

41 Não se quer dizer que a exigência em tela desborda do poder de polícia da Administração Pública. Na medida em que veio a lume a onda de acessibilidade, é legítimo ao Estado, se não uma imposição, viabilizar caminhos e estabelecer alguns parâmetros ao exercício desses "novos" direitos. Todavia, da forma como exercido no caso concreto, uma exigência legítima pode ser irracional, pois que, sobre estar voltada a um determinado universo de pessoas, a cautela recomenda não criar certezas com base em aparências.

42 Sobre a diferença dentre valores, princípios e normas, cf. SALDANHA, Nelson. Filosofia do direito. 2. ed. Rio de Janeiro: Renovar, 2005. p. 226 e ss.

43 DWORKIN, Ronald. Levando os direitos a sério. Tradução de Nelson Boeira. São Paulo: Martins Fontes, 2005. p. 139.

44 Dworkin alega que caso difícil é constituído por aquela situação em que o julgador deve reconhecer que está, em certa medida, incerto quanto às possibilidades que deve aplicar ao caso e, nessa hipótese, decide com base na argumentação que lhe parecer conveniente ou mais forte (DWORKIN, Ronald. Levando os direito a sério. São Paulo: Martins Fontes, 2002. p. 111). 


\section{REFERÊNCIAS}

ABBAGNANO, Nicola. Dicionário de filosofia. São Paulo: Martins Fontes, 2007.

ALEXY, Robert. Teoria dos direitos fundamentais. 2. ed. Tradução de Virgílio Afonso da Silva. São Paulo: Malheiros, 2011.

ALMEIDA, Gregório Assagra de. Direito material coletivo: superação da Summa Divisio Direito Público e Direito Privado por uma nova Summa Divisio Constitucionalidade. Belo Horizonte: Del Rey, 2008.

ÁVILA, Humberto. Teoria dos princípios: da definição à aplicação dos princípios jurídicos. 11. ed. São Paulo: Malheiros, 2010.

BASTOS, Ronaldo. O conceito do direito em Marx. Porto Alegre: Sergio Antonio Fabris Ed., 2012.

BODIN DE MORAES, M. C. O conceito de dignidade humana: substrato axiológico e conteúdo normativo. In: SARLET, Ingo Wofgang. (Org.). Constituição, direitos fundamentais e direito privado. Porto Alegre: Livraria do Advogado, 2003.

CANTALI, Fernanda Borghetti. Direitos da personalidade: disponibilidade relativa, autonomia privada e dignidade humana. Porto Alegre: Livraria do Advogado, 2009.

COMPARATO, Fabio Konder. A afirmação histórica dos direitos humanos. 6. ed. rev. e atual. São Paulo: Saraiva, 2008.

DESCARTES, René. O discurso do método. São Paulo: Ed. Escala, [s/d].

DILTHEY, Wilhelm. Introdução às ciências humanas: tentativa de uma fundamentação para o estudo da sociedade e da história. Rio de Janeiro: Editora Forense Universitária, 2010. 
DIMOULIS, Dimitri. Positivismo jurídico: introdução a uma teoria do direito e defesa do pragmatismo jurídico-político. São Paulo: Método, 2006.

DIMOULIS, Dimitri; MARTINS, Leonardo. Teoria geral dos direitos fundamentais. São Paulo: RT, 2008.

DWORKIN, Ronald. Levando os direito a sério. São Paulo: Martins Fontes, 2002.

FERRAZ JR., Tércio Sampaio. Introdução ao estudo do direito: técnica, decisão, dominação. 4. ed. São Paulo: Atlas, 2003.

GADAMER, Hans-Georg. O problema da consciência histórica. 3. ed. Rio de Janeiro: Editora FGV, 2009.

GRAU, Eros Roberto. Ensaio e discurso sobre a interpretação/aplicação do direito. 3. ed. São Paulo: Malheiros, 2005.

HEIDEGGER, Martin. Ontologia: hermenêutica da faticidade. Petrópolis: Vozes, 2012.

KANT, Immanuel. Fundamentação da metafísica dos costumes e outros escritos. Tradução de Leopoldo Holzbach. São Paulo: Martin Claret, 2006.

MARINONI, Luiz Guilherme. Teoria geral do processo. 2. ed. São Paulo: RT, 2006.

MARMELSTEIN, George. Curso de direitos fundamentais. 3. ed. São Paulo: Atlas, 2011.

MAZZILI, Hugo Nigro. A defesa dos interesses difusos em juízo: meio ambiente, consumidor, patrimônio cultural e patrimônio público e outros interesses. 15. ed. São Paulo: Saraiva, 2002.

MELLO, Celso Antônio Bandeira de. Conteúdo jurídico do princípio da igualdade. 3. ed. São Paulo: Malheiros, 2006. 
OLIVEIRA, Manfredo A. de. Reviravolta linguístico-pragmática na filosofia contemporânea. 3. ed. São Paulo: Edições Loyola, 2006.

PEREIRA, Mateus Costa; ALVES, Pedro Spíndola. Bezerra. A dignidade da pessoa humana com deficiência: reflexos práticos da acessibilidade enquanto direito fundamental. Revista Brasileira de Tradução Visual (RBTV), v. 14, p. 1-16, 2013.

. Redefinição constitucional de pessoa com deficiência e o direito à diferença. Revista Brasileira de Tradução Visual (RBTV), v. 15, p. 18-35, 2013.

REALE, Giovanni; ANTISERI, Dario. História da filosofia. São Paulo: Paulus, 1991. v. III.

REGO, G. B. Os princípios fundamentais e sua natureza estruturante na constituição de 1988. Anuário dos Cursos de Pós-Graduação em Direito, Recife: Editora Universitária da UFPE, ano 8, n. 8, 1999.

SALDANHA, Nelson. Filosofia do direito. 2. ed. Rio de Janeiro: Renovar, 2005.

. Ordem e hermenêutica. 2. ed. Rio de Janeiro: Renovar, 2003.

. Teoria do direito e crítica histórica. Rio de Janeiro: Freitas Bastos, 1987.

SARLET, Ingo Wolfgang. As dimensões da dignidade da pessoa humana: construindo uma compreensão jurídico-constitucional necessária e possível. Revista Brasileira de Direito Constitucional, São Paulo, n. 9, jan./jun. 2007.

Dignidade da pessoa humana e direitos fundamentais na Constituição Federal de 1988. Porto Alegre: Livraria do Advogado, 2009. 
SASSAKI, Romeu Kazumi. Inclusão: construindo uma sociedade para todos. 8. ed. Rio de Janeiro: WVA, 2010.

SILVA, Virgílio Afonso da. Direitos fundamentais: conteúdo essencial, restrições e eficácia. São Paulo: Malheiros, 2009.

Artigo recebido em: 25-3-2012

Aprovado em: 16-12-2013

\section{Mateus Costa Pereira}

Mestre em Teoria do Processo e Direito Processual pela Universidade Católica de Pernambuco (Unicap); professor de Direito Processual Civil na Graduação e Pós-Graduação lato sensu da Unicap. Professor visitante da Pós-Graduação da Autarquia do Ensino Superior de Garanhuns (Aesga); professor da Escola Superior de Advocacia Ruy Antunes da OAB/ PE (Esary); membro da Comissão de Defesa dos Direitos das Pessoas com Deficiência da OAB-PE (2013).

\section{UNICAP}

Rua Almeida Cunha, 245 - Bloco G4 $3^{\circ}$ andar, sala 304, Boa Vista, Recife/ PE - CEP: 50.050-480.

E-mail: matpzen@gmail.com

\section{Ronaldo Bastos}

Mestre em Direito pela Universidade Federal de Pernambuco; professor do Centro Universitário Maurício de Nassau (UNINASSAU), em Recife; servidor do Tribunal de Justiça de Pernambuco desde 2009.

Tribunal de Justiça do Estado de Pernambuco, Avenida Barreto de Menezes. Prazeres. CEP 54330-000 Jaboatao dos Guararapes - PE. E-mail: ronaldocbjr@yahoo.com.br

\section{Pedro Spíndola B. Alves}

Mestrando na linha de Direito e Linguagem pela Universidade Federal de Pernambuco; advogado.

Av. Prof. Moraes Rego, 1235 - Cidade Universitária, Recife - PE - CEP: 50670-901.

E-mail: pedrospindola.adv@gmail.com 
